\title{
Bioeffects of metals and their forms
}

\section{BIOLOGICAL EFFECTS IN WHEAT (Triticum vulgare L.) UNDER THE INFLUENCE OF METAL NANOPARTICLES (Fe, Cu, Ni) AND THEIR OXIDES $\left(\mathrm{Fe}_{3} \mathrm{O}_{4}, \mathrm{CuO}, \mathrm{NiO}\right)$}

\author{
A.M. KOROTKOVA ${ }^{1,2}$, S.V. LEBEDEV 2 , F.G. KAYUMOV 2 , E.A. SIZOVA ${ }^{1,2}$ \\ ${ }^{1}$ Orenburg State University, Institute of Bioelementology, 13, prosp. Pobedy, Orenburg, 460018 Russia, e-mail \\ anastasiaporv@mail.ru, lsv74@list.ru; \\ ${ }^{2}$ All-Russian Research Institute of Beef Cattle Breeding, Federal Agency of Scientific Organizations, 29, ul. 9 Yan- \\ varya, Orenburg, 460000 Russia, e-mail sizova-178@ya.ru \\ ORCID: \\ Korotkova A.M. orcid.org/0000-0002-7981-7245 \\ Lebedev S.V. orcid.org/0000-0001-9485-7010 \\ Sizova E.A. orcid.org/0000-0002-5125-5981 \\ The authors declare no conflict of interests \\ Acknowledgements: \\ Supported by Russian Science Foundation (project № 14-36-00023) \\ Received June 9, 2016 \\ Kayumov F.G. orcid.org/0000-0001-9241-9228
}

\section{Abstract}

In recent decades, the development of nanotechnology has led to the need for a thorough study of ultrafine metal security. It is known that many of ultrafine metals have pro-oxidant and toxic properties. However, no studies have been performed to comprehensively compare of how the metal and metal oxide nanoparticles (NP) affect plants. We first examined complex morphophysiological parameters in wheat (Triticum vulgare L.) seedlings exposed for 2 days to spherical nanoparticles (NPs) of $\mathrm{Fe}^{0}$ or $\mathrm{Fe}_{3} \mathrm{O}_{4}, \mathrm{Cu}^{0}$ or $\mathrm{CuO}$, and $\mathrm{Ni}^{0}$ or $\mathrm{NiO}$ at 0.0125 to $1.0 \mathrm{M}$ concentrations. Analysis of metric characteristics showed that the sensitivity to $\mathrm{Cu}^{0} \mathrm{NP}$ and $\mathrm{Ni}^{0} \mathrm{NP}$ was much higher than that to their oxides $(\mathrm{CuO}, \mathrm{NiO})$. NiO NP and $\mathrm{CuO} \mathrm{NP}$ had no lethal effects at all tested concentrations though caused a significant (more than 2-fold) reduction in most of the growth parameters. At low (less than $0.05 \mathrm{M}$ ) levels of $\mathrm{Fe} \mathrm{NP}$ and $\mathrm{Fe}_{3} \mathrm{O}_{4} \mathrm{NP}$ the seedlings showed a significantly stimulated growth as compared to control. In contrast, the $\mathrm{Cu}^{0} \mathrm{NP}, \mathrm{CuO} \mathrm{NP}, \mathrm{Ni}^{0} \mathrm{NP}$ and $\mathrm{NiO} \mathrm{NP}$ caused toxic effect on growth which increased as the metal level elevated. The analysis showed a high sensitivity of roots, as the first target for the toxic agents, to low metal concentrations. At low $\mathrm{Cu}^{0} \mathrm{NP}$, $\mathrm{CuO} \mathrm{NP}, \mathrm{NiO} \mathrm{NP}$ and $\mathrm{Ni}^{0} \mathrm{NP}$ levels in the medium, the root growth was 19 times, 7.4 times, 4.8 times and 2.2 times lower as compared to control. Basing on morphological parameters, the nanoparticles were arranged in the following ascending order of their toxicity for growth of the main root and the first leaf in $T$. vulgare: $\mathrm{Fe}_{3} \mathrm{O}_{4} \rightarrow \mathrm{Fe}^{0} \rightarrow \mathrm{NiO} \rightarrow \mathrm{CuO} \rightarrow \mathrm{Ni}^{0} \rightarrow \mathrm{Cu}^{0}$. Analysis of photosynthetic pigments showed that a 2-day exposure to $\mathrm{Fe} N P$ and $\mathrm{Fe}_{3} \mathrm{O}_{4} \mathrm{NP}$ led to generally more positive and stable effects on pigments as compared to copper and nickel. In the presence of less than $0.05 \mathrm{M}$ metal the seedlings were green with a marked stimulation of pigmentation. At the same time, there was the strongest negative effect of the $\mathrm{Cu}$ NP on chlorophyll a (22.0-33.0\%), and Ni NP on chlorophyll b (16.0-68.0\%). The influence of $\mathrm{CuO}$ toward lower chlorophyll content was dosedependent: a statistically significant decrease in chlorophyll a was observed at $0.05,0.1$ and $0.5 \mathrm{M}$ (9.0-21.5\%), and in chlorophyll $\mathrm{b}$ at 0.0125 and $0025 \mathrm{M}(4.0-15.0 \%)$. NiO NP had insignificant inhibitory effect on chlorophylls at $8.7 \%$ decrease. Carotenoids were less sensitive to tested nanoparticles as compared to chlorophylls. Analysis of MDA content in the seedlings showed that nanoparticles influenced lipid peroxidation in the roots rather than in leaves. The effect of MDA accumulation in roots was the most apparent after exposure to some $\mathrm{NPs}$, especially $\mathrm{Ni}^{0} \mathrm{NP}, \mathrm{Su}^{0} \mathrm{NP}$ and $\mathrm{CuO} \mathrm{NP}$ which caused MDA increase exceeding control by $17.0 \%, 25.0 \%$ and $18.7 \%$, respectively. The $\mathrm{Fe}^{0}$, $\mathrm{Fe}_{3} \mathrm{O}_{4}$ and $\mathrm{NiO}$ NPs did not affect the MDA content, whereas $\mathrm{Fe}_{3} \mathrm{O}_{4} \mathrm{NP}$ reduced the MDA level by $30.0 \%$. Thus $\mathrm{Fe}^{0}, \mathrm{Fe}_{3} \mathrm{O}_{4}, \mathrm{Cu}^{0}, \mathrm{CuO}, \mathrm{Ni}^{0}$ and $\mathrm{NiO}$ nanoparticles selectively affect cell metabolism and exhibit different biological activity depending on chemical composition and concentrations.

Keywords: Triticum vulgare L., metal nanoparticles, growth rates, photosynthetic pigments, malondialdehyde, lipid peroxidation

Despite the multi-level intracellular protection of cells from stress, when affected with adverse factors, the concentration of reactive oxygen species (ROS) 
in plants increases and a cascade mechanism of oxidative stress is triggered, leading to the destruction of vital cellular components and to cell death. Plants are constantly exposed to ROS, especially in the presence of nanoparticles (NPs) of metals [1]. Using various mechanisms, most species have the ability to adapt to NPs of metals [2]. However, these are not sufficient to prevent oxidative stress and the manifestation of cyto- and genotoxic effects.

It has been shown that the $\mathrm{Cu}^{0}$ nanoparticles at a high concentration $(1,000$ $\mathrm{mg} / \mathrm{l}$ ) adversely affect the growth of the bean seedlings, penetrate through the cell membrane and form aggregates with cellular components [3]. Nanoparticles containing $\mathrm{Cu}^{0}$ and $\mathrm{Cu}_{2} \mathrm{O}$ can block water channels by adsorption and increase the inflow of ROS into the roots of onions, which in turn disrupts the cell division and metabolism [4]. In an experiment with Triticum aestivum, the inhibition of shoot growth after exposure to the $\mathrm{Cu}^{0} \mathrm{NPs}$ at various concentrations [5] was described. It was also reported that as the concentration of the $\mathrm{Cu}^{0} \mathrm{NPs}$ and their agglomerates increased, the rates of bioaccumulation of this element in plants was elevated.

Previously, we have compared the effects of the $\mathrm{Fe}^{0}$ NPs (diameter $80 \pm 5 \mathrm{~nm}$ ), $\mathrm{Fe}_{3} \mathrm{O}_{4}$ (width 50-80 nm, height 4-10 nm) and the $\mathrm{FeSO}_{4}$ (II) solution on common wheat (Triticum vulgare L.) plants [6]. At the same time, the greatest susceptibility (decrease in seed germination, suppression of leaf growth, and decrease in the amount of pigments in seedlings) was recorded with increasing ferric sulfate (II) concentration in the medium, and there were differences observed between the effects of nanoparticles, such as the germination activity was more strongly affected by $\mathrm{Fe}^{0} \mathrm{NPs}$, and the length of the leaves and the amount of pigments by $\mathrm{Fe}_{3} \mathrm{O}_{4}$ NPs.

Toxicity of water-soluble metal nanoparticles is associated primarily with a high redox potential of ions and oxidation of biological molecules. The most important factor is the ability of nanoparticles to induce oxidative stress, i.e. to generate ROS [7]. When studying the oxidative damage of plant cells after treatment with the CuO NPs, it was established that the effect occurred not in ions of copper, but in its oxide, because of its limited solubility in the growth medium [8]. In the roots of tomato plants, after incubation with NiO NPs, a high pool of ROS and increased lipid peroxidation (by 39.3 to $49.5 \%$ vs. control) were found in the protoplast [9]. However, an attempt to distinguish between oxidative induction either by $\mathrm{NiO}$ oxide or nickel ions failed, since both of these compounds were available in the root cells. It has been suggested that $\mathrm{Ni}^{2+}$ ions generate in plants the $\mathrm{HO}^{--}$radical through the Haber-Weiss reaction.

In recent years, it has been established that oxidative stress can be caused by nanoparticles of many metals (silver, gold, iron), or ferrites, as well as oxides of zinc, nickel, copper, iron, titanium and silicon. The main attention is focused on studying the absorption of nanometals and plant growth rates after exposure to nanoparticles of metals and their oxides. Comprehensive studies revealing the mechanisms of phytotoxic properties of nanoparticles of transition metals (iron, copper and nickel) in comparison with their oxide forms have not been previously conducted.

In this paper, we present for the first time an approach to a comparative assessment of the toxicity of nanoforms based on $\mathrm{Fe}, \mathrm{Cu}$, and $\mathrm{Ni}$, taking into account not only the morphological characteristics of plants, but also important physiological stress markers such as the activity of the photosynthetic apparatus and the degree of peroxide oxidation of membrane lipids.

The aim of the study was to assess morphophysiological indices in wheat seedlings in response to the effects of the nanoparticles of iron, copper, nickel 
and their oxides at various concentrations.

Techniques. The research used commercially available spherical nanoparticles of iron $\mathrm{Fe}^{0}$, copper $\mathrm{Cu}^{0}$, nickel $\mathrm{Ni}^{0}$ and their $\mathrm{Fe}_{3} \mathrm{O}_{4}, \mathrm{CuO}$ and $\mathrm{NiO}$, produced by electric explosion of a conductor in an argon atmosphere. Material research testing of the preparations (particle size, polydispersity, volume, quantitative content of fractions, surface area) included electronic scanning, translucent and atomic force microscopy using LEX T OLS4100, JSM 7401F, JEM2000FX (JEOL, Japan). Particle size distribution was investigated using a Brookhaven 90Plus/BIMAS ZetaPALS and a Photocor Compact nanoparticles analyzer (Photocor, Russia) in lyosoles obtained after treatment with the ultrasonic disperser UZDN-2T (NPP Akadempribor, Russia) for $30 \min (35 \mathrm{kHz}$, $300 \mathrm{~W}$, amplitude of oscillations of $10 \mu \mathrm{A}$ ).

Wheat (Triticum vulgare L.) seeds were disinfected with $0.01 \% \mathrm{KMnO}_{4}$ solution for $5 \mathrm{~min}$ and, after triple washings with distilled water, placed on a substrate of filter paper in plastic Petri dishes $(9 \mathrm{~cm}$ in diameter $), 20$ pieces each, at a distance of at least $0.5-1.5 \mathrm{~cm}$ from each other. For the relative synchronization of growth, equally sprouted seeds were chosen and transferred to wet filter paper in separate plastic dishes. Within 1 day, plants were in new conditions without additional influences. On day $3,5 \mathrm{ml}$ of a suspension of the nanoparticles of $\mathrm{Fe}^{0}, \mathrm{Cu}^{0}, \mathrm{Ni}^{0}$ and $\mathrm{Fe}_{3} \mathrm{O}_{4}, \mathrm{CuO}$ и $\mathrm{NiO}$ oxides in dilutions to a metal concentration of 0.0125 to $1.0 \mathrm{M}$ were added to the dishes with sprouts. The suspensions were pre-sonicated at $35 \mathrm{KHz}$ in a Sapphire TTC bath-type source (ZAO PKF Sapphire, Russia) for $30 \mathrm{~min}$. A group of control plants was kept in distilled water. In this setting, shoots were not contacted with nanoparticles, which could enter the plant only through the roots. After the addition of the nanoparticle suspension, to uniformly distribute them in the media, the Petri dishes were shaken in the ST-3M thermal shaker (Elmi, Latvia) for $5 \mathrm{~min}$. The control and study samples prepared this way were left in a climatic chamber (Agilent, USA) at 12-hour illumination, $22 \pm 1{ }^{\circ} \mathrm{C}$ and humidity $80 \pm 5 \%$ for 3 days, and not allowing to dry [6].

On day 5, after the breakthrough of the coleoptile, physiological and biochemical indices were evaluated. In 10 sprouts, the ruler was used to measure the length of the 1st leaf (from the base to the apex of the main leaf) and the main root (from the root neck to the tip of the main root) within the accuracy of $1 \mathrm{~mm}$. Three plants from each variant were selected to determine the content of photosynthetic pigments (PPs) and oxidative stress indicators.

The amount of PPs was measured in ethanol extracts using the spectrophotometric method according to the standard procedure [10]. The leaves of the sprouts (one leaf from each of 10 sprouts from each sample) weighing $30 \mathrm{~g}$ were quickly cut with scissors and homogenized in a chilled mortar with $\mathrm{CaCO}_{3}$, calcined quartz sand and a small amount $(2-3 \mathrm{ml})$ of $96 \%$ ethyl alcohol. After precipitation (the K-23 centrifuge, GDR), about $20 \mathrm{ml}$ of $96 \%$ ethyl alcohol was re-added to the resulting suspension and homogenized once again. For maximum extraction of pigments, this procedure was repeated 2-4 times (to almost complete transparency of the extractant) and the extracts obtained for each sample were combined. Insoluble particles were separated by centrifugation, and $96 \%$ ethanol was added to the extract until the predetermined final volume. The absorbance of the extracts was determined on a single-beam automated photometer KFK-3 (Russia) at various wavelengths (665 nm, $649 \mathrm{~nm}$ and $450.5 \mathrm{~nm}$ ) corresponding to maximum absorbance of chlorophyll $a$, chlorophyll $b$ and carotenoids.

The lipid peroxidation (LPO) was assessed by the accumulation of the product of the malonic dialdehyde (MDA) reaction with thiobarbituric acid (TBA) 
(Lenreactiv, Russia). The evaluation was carried out using a method based on the measurement of a colored trimethine complex using trichloroacetic acid (TCA; Reachim, Russia) at $\lambda=532 \mathrm{~nm}$ [11]. To accomplish this, $100 \mathrm{mg}$ of wheat tissue was homogenized with $200 \mu \mathrm{l}$ of $20 \%$ TCA. The resulting homogenate was centrifuged for $5 \mathrm{~min}$ at $12,000 \mathrm{~g}$. The supernatant was used as a sample for analysis. $100 \mu \mathrm{l}$ of the supernatant were added to each of the two tightly closed test tubes. $100 \mu \mathrm{l}$ of $20 \%$ TCA was added to one of the samples, it served as a control in spectrophotometric measurements. To another sample, $100 \mu \mathrm{l}$ of $0.5 \%$ TBA solution was added. The samples were incubated in a boiling water bath $\left(100{ }^{\circ} \mathrm{C}\right)$ for $30 \mathrm{~min}$, and then cooled at room temperature.

Lab experiments were performed in a 3-fold biological replication, analytical determination for each sample in triplicate. The reliability of the experimental data was assessed by mathematical statistics using Statistica 10.0 application software package (StatSoft, Inc., USA). The arithmetic mean $(M)$ with the standard error of the mean $(m)$ are presented.

Results. The results of nanoparticles qualification are shown in Table 1.

1. The characteristics of metal-containing nanopowders used in the study $(M \pm m)$

\begin{tabular}{l|c|c|c}
\hline Preparation & $\begin{array}{l}\text { Average size, } \\
\mathrm{nm}\end{array}$ & $\begin{array}{l}\text { Specific surface } \\
\left(\mathrm{S}_{\mathrm{spec}}\right), \mathrm{m}^{2} / \mathrm{g}\end{array}$ & $\begin{array}{l}\zeta \text { - potential, } \\
\mathrm{mV}\end{array}$ \\
\hline $\mathrm{Fe}^{01}$ & $70 \pm 4.12$ & 7.7 & $13 \pm 0.5$ \\
$\mathrm{Fe}_{3} \mathrm{O}_{4}{ }^{1}$ & $76 \pm 3.11$ & 10.1 & $19 \pm 0.5$ \\
$\mathrm{Cu}^{02}$ & $54 \pm 2.06$ & 12.5 & $31 \pm 0.1$ \\
$\mathrm{CuO}^{2}$ & $65 \pm 2.45$ & 14 & $47 \pm 0.1$ \\
$\mathrm{Ni}^{0} 1$ & $57 \pm 1.15$ & $4.5-6.0$ & $25 \pm 0.5$ \\
$\mathrm{NiO}^{2}$ & $68 \pm 2.21$ & 12 & $29 \pm 0.5$
\end{tabular}

N o t e. Manufacturers: 1 - OOO Plasmotherm (Russia), 2 - Powder Advanced Technologies LLC (Russia).

The linear growth of plants is an important indirect characteristic of the intensity of cell division or stretching. We analyzed the metric indices in sprouts after 2 days of exposure to different concentrations of NPs of metals and their oxides (Fig. 1).

The high resistance of plants was observed when affected with iron-containing nanoparticles, which was expressed in a significant

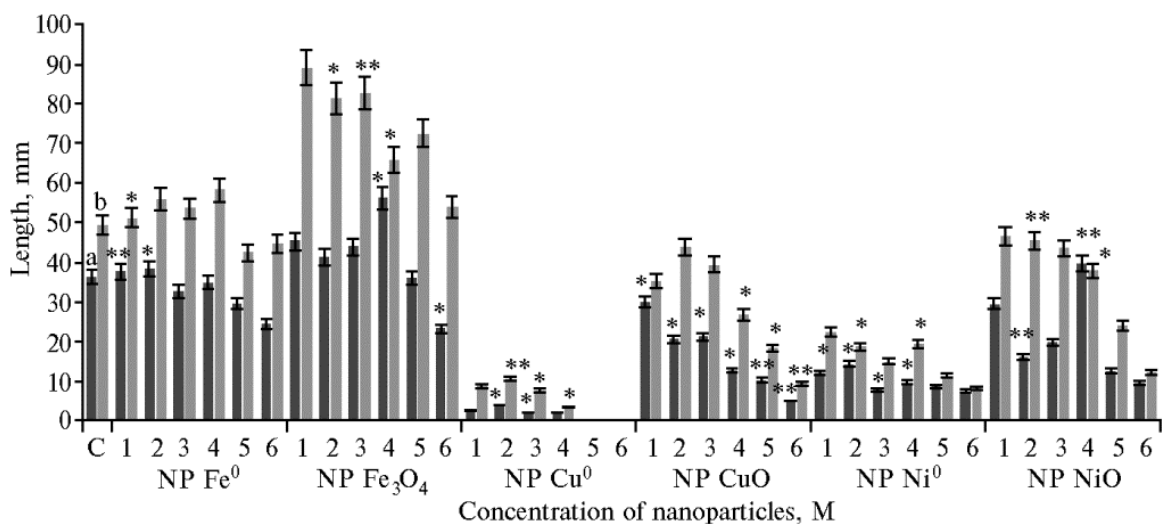

Fig. 1. Length of the main root (a) and 1st leaf (b) in wheat (Triticum vulgare L.) sprouts after a 2-day incubation with nanoparticles of metals and their oxides in different concentrations: $1-0.0125 \mathrm{M}, 2-$ $0.025 \mathrm{M}, 3-0.05 \mathrm{M}, 4-0.1 \mathrm{M}, 5-0.5 \mathrm{M}, 6-1.0 \mathrm{M}$; C - control.

$*, * *$ Differences vs. control are significant at $\mathrm{p} \leq 0.05$ and $\mathrm{p} \leq 0.01$, respectively..

promotion of growth of sprouts in comparison to the control. Therefore, in the presence of $0.0125 \mathrm{M} \mathrm{Fe}^{0} \mathrm{NPs}$, the length of the 1st leaf and the main root exceeded the values in the controls by $3.5(\mathrm{p}<0.01)$ and $3.6 \%(\mathrm{p}<0.05)$, respectively. In addition, nanoparticles promoted root growth (by $5.7 \%$, p $<0.05$ ). At the same time, a significant increase in the length of the 1st leaf compared to the control was observed in the presence of $\mathrm{Fe}_{3} \mathrm{O}_{4}$ NPs at concentrations of 0.025 and $0.05 \mathrm{M}$, by $39.0(\mathrm{p}<0.05)$ and $40.0 \%(\mathrm{p}<0.01)$, respectively. A 2- 
fold increase in the metal concentration $(0.1 \mathrm{M})$ promoted the growth of the root and leaf (by 35.0 and $25.0 \%$, respectively, p < 0.05 ). At the maximum concentration of the $\mathrm{Fe}_{3} \mathrm{O}_{4}$ NPs $(1.0 \mathrm{M})$, the root length decreased by $56.0 \%$ $(\mathrm{p}=0.05)$.

On the contrary, when using nanoparticles of $\mathrm{Cu}^{0}$ and $\mathrm{CuO}, \mathrm{Ni}^{0}$ and $\mathrm{NiO}$, a toxic effect developed which was enhanced with an increase in the amount of metal in the solution.

The presence of the $\mathrm{Cu}^{0}$ NPs in the aqueous phase in concentrations of 0.5 and $1.0 \mathrm{M}$ completely inhibited the growth of the sprout and root and even in minimal dilutions it markedly decreased this value. A significant inhibition of the growth of the 1st leaf was noted in options with $0.025 ; 0.05$ and $0.1 \mathrm{M} \mathrm{Cu}^{0}$ NPs with 4.7 ( $\mathrm{p}<0.01), 6.5$ and 14.5 times $(\mathrm{p}<0.05)$ decrease vs. control, respectively, and the growth of the root at 0.025 and $0.05 \mathrm{M} \mathrm{Cu}^{0} \mathrm{NPs}$ decreased 9.8 and 19.0 times $(\mathrm{p} \leq 0.05)$. The addition of $0.05,0.1$ and $1.0 \mathrm{M} \mathrm{CuO} \mathrm{NPs}$ significantly affected the leaf length resulting in 1.8 -fold, 2.7 -fold $(p<0.05)$ and 5.3-fold ( $\mathrm{p}<0.01)$ decrease, respectively, when compared to the control samples. The main root was 1.2-7.4 times $(\mathrm{p}<0.05)$ shorter than in the control for all dilutions of nanoparticles.

The nanoparticles of $\mathrm{Ni}^{0}$ at doses of 0.025 and $0.1 \mathrm{M}$ caused a significant 2.6-fold and 2.5-fold ( $p<0.05$ ) decrease in the leaf length. The root of the plants developed poorly at all the concentrations of $\mathrm{Ni}^{0}$ NPs and was 2.5-4.8fold shorter than in the control $(\mathrm{p}<0.05)$. The effect of nanoparticles of nickel oxide turned out to be weaker and was debatable: NiO NPs at concentrations of 0.025 and $0.1 \mathrm{M}$ inhibited the growth of the aerial part by $8.0(\mathrm{p}=0.01)$ and $3.4 \%(\mathrm{p}<0.05)$, at concentrations of 0.025 and $0.05 \mathrm{M}$ slowed the growth of the root part 2.2 and 1.8 times, whereas the concentration of $0.1 \mathrm{M}$, on the contrary, led to an increase in the root length by $7.0 \%$.

The content of PPs in plants can be a more informative indicator of the toxicity of NPs compared with growth rates. In our experiments, the amount of PPs varied depending on the type and concentration of nanoparticles and was not always correlated with the dynamics of the length of the 1st leaf.

After 2 days of exposure of sprouts to the $\mathrm{Fe}^{0}$ and $\mathrm{Fe}_{3} \mathrm{O}_{4}$ nanoforms, the effect on the pigment content was generally more favorable and stable than when using copper- and nickel-based nanomaterials. Thus, after the incubation in $\mathrm{Fe}^{0}$ NPs and $\mathrm{Fe}_{3} \mathrm{O}_{4}$ NPs at a concentration of $<0.05 \mathrm{M}$, the green color of the sprouts was preserved and even the synthesis of pigments increased. The content of chlorophylls $a$ and $b$ was significantly increased compared to the control: by 1.5-7.6 and 2.6-16.5\% ( $\mathrm{p} \leq 0.05)$, as influenced by $0.0125-0.05 \mathrm{M} \mathrm{Fe}^{0} \mathrm{NPs}$, and by $2.0-11.7(\mathrm{p}<0.05)$ and $1.0 \%(\mathrm{p}=0.001)$ at 0.0125 and $0.05 \mathrm{M} \mathrm{Fe}_{3} \mathrm{O}_{4}(\mathrm{Ta}-$ ble 2). The sum of chlorophylls increased by 1.9-7.0\% under the influence of both forms of nanoparticles. At 0.5 and $1 \mathrm{M}$, the amount of chlorophyll $a$ decreased for $\mathrm{Fe}^{0} \mathrm{NPs}$ and $\mathrm{Fe}_{3} \mathrm{O}_{4}$ on average by 13.0-17.0 and $2.0 \%$ (p $\leq 0.05$ ), while the content of chlorophyll $b$ did not change significantly.

With a similar effect of $\mathrm{Cu}^{0} \mathrm{NPs}$, along with a significant suppression of the growth and the development of a dark brown coloration of the leaves, a decrease in the content of green pigments was recorded on average by $19.0 \%$ $(\mathrm{p}<0.05) . \mathrm{Cu}^{0}$ NPs caused a decrease in the chlorophyll $a$ content by $22.0-$ $33.0 \%$, even at a concentration that was 4 times lower than the maximum sublethal dose $(0.0125 \mathrm{M})$ (see Table 2$)$. At the same time, the amount of chlorophyll $b$ remained close to the control or changed insignificantly.

In the option with the $\mathrm{CuO}$ NPs, an overall decrease in the total amount of pigments even after exposure to low concentrations $(<0.05 \mathrm{M})$ was $11.8 \%$ vs. 
control. It should be noted that the $\mathrm{CuO}$ NPs influenced the amount of chlorophyll $b(4.0-30.0 \%)$ to a greater extent than the $\mathrm{Cu}^{0}$ NPs. A statistically significant decrease in the chlorophyll $a$ content vs. control, i.e. by $9.0 \%(\mathrm{p}<0.05)$, $10.5 \%(\mathrm{p}=0.01)$ and $21.5 \%(\mathrm{p}=0.05)$, was noted at $0.05,0.1$ and $0.5 \mathrm{M}$, respectively, and in the chlorophyll $b$ content by $4.0 \%(\mathrm{p}<0.05)$ and $15.0 \%$ $(\mathrm{p}=0.05)$ at 0.0125 and $0.025 \mathrm{M}$, respectively.

2. The content of photosynthetic pigments $(\mathrm{mg} / \mathrm{g}$ wet weight) in wheat (Triticum vulgare L.) leaves after 2 days of incubation of sprouts with nanoparticles (NP) of metals and their oxides in different concentrations $(M \pm m)$

\begin{tabular}{|c|c|c|c|c|}
\hline Option & NP concentration, $\mathrm{M}$ & Chlorophyll $a$ & Chlorophyll b & Carotenoids \\
\hline Control & & $1.585 \pm 0.14$ & $0.591 \pm 0.16$ & $0.278 \pm 0.04$ \\
\hline \multirow[t]{6}{*}{$\mathrm{Fe}^{0}$} & 0.0125 & $1.611 \pm 0.04^{*}$ & $0.607 \pm 0.03 *$ & $0.281 \pm 0.01 *$ \\
\hline & 0.025 & $1.609 \pm 0.01^{* * *}$ & $0.708 \pm 0.01^{*}$ & $0.397 \pm 0.05^{*}$ \\
\hline & 0.05 & $1.716 \pm 0.05^{*}$ & $0.622 \pm 0.02 * *$ & $0.304 \pm 0.11$ \\
\hline & 0.1 & $1.244 \pm 0.22$ & $0.473 \pm 0.21$ & $0.296 \pm 0.04^{*}$ \\
\hline & 0.5 & $1.402 \pm 0.21^{*}$ & $0.441 \pm 0.18$ & $0.273 \pm 0.05^{*}$ \\
\hline & 1.0 & $1.352 \pm 0.18^{*}$ & $0.463 \pm 0.12$ & $0.268 \pm 0.12$ \\
\hline \multirow[t]{4}{*}{$\mathrm{Cu}^{0}$} & 0.0125 & $1.295 \pm 0.10^{*}$ & $0.569 \pm 0.22$ & $0.369 \pm 0.08$ \\
\hline & 0.025 & $1.209 \pm 0.03^{*}$ & $0.595 \pm 0.09$ & $0.372 \pm 0.12$ \\
\hline & 0.05 & $1.192 \pm 0.02 *$ & $0.586 \pm 0.04^{*}$ & $0.281 \pm 0.05^{*}$ \\
\hline & 0.1 & $1.284 \pm 0.06^{*}$ & $0.579 \pm 0.09$ & $0.299 \pm 0.02^{*}$ \\
\hline \multirow[t]{6}{*}{$\mathrm{Ni}^{0}$} & 0.0125 & $1.581 \pm 0.20$ & $0.588 \pm 0.02^{* *}$ & $0.275 \pm 0.13$ \\
\hline & 0.025 & $1.448 \pm 0.03^{*}$ & $0.508 \pm 0.07$ & $0.269 \pm 0.01^{*}$ \\
\hline & 0.05 & $1.452 \pm 0.14^{*}$ & $0.406 \pm 0.04^{*}$ & $0.276 \pm 0.04 *$ \\
\hline & 0.1 & $1.434 \pm 0.05^{* *}$ & $0.383 \pm 0.03^{* * *}$ & $0.273 \pm 0.05^{*}$ \\
\hline & 0.5 & $1.394 \pm 0.94$ & $0.397 \pm 0.15$ & $0.254 \pm 0.03^{* *}$ \\
\hline & 1.0 & $1.398 \pm 0.18$ & $0.352 \pm 0.01^{*}$ & $0.272 \pm 0.04^{*}$ \\
\hline \multirow[t]{6}{*}{$\mathrm{Fe}_{3} \mathrm{O}_{4}$} & 0.0125 & $1.621 \pm 0.04^{*}$ & $0.597 \pm 0.07$ & $0.288 \pm 0.19$ \\
\hline & 0.025 & $1.796 \pm 0.03^{* *}$ & $0.548 \pm 0.08$ & $0.281 \pm 0.13$ \\
\hline & 0.05 & $1.583 \pm 0.23$ & $0.552 \pm 0.12$ & $0.289 \pm 0.16$ \\
\hline & 0.1 & $1.534 \pm 0.12$ & $0.581 \pm 0.14$ & $0.273 \pm 0.14$ \\
\hline & 0.5 & $1.564 \pm 0.01^{* *}$ & $0.563 \pm 0.06$ & $0.286 \pm 0.05^{* *}$ \\
\hline & 1.0 & $1.552 \pm 0.02^{*}$ & $0.534 \pm 0.08$ & $0.292 \pm 0.03^{*}$ \\
\hline \multirow[t]{6}{*}{$\mathrm{CuO}$} & 0.0125 & $1.524 \pm 0.09$ & $0.567 \pm 0.04^{* *}$ & $0.285 \pm 0.15$ \\
\hline & 0.025 & $1.548 \pm 0.31$ & $0.512 \pm 0.03^{*}$ & $0.251 \pm 0.12$ \\
\hline & 0.05 & $1.452 \pm 0.05^{*}$ & $0.476 \pm 0.05^{* *}$ & $0.259 \pm 0.02 * *$ \\
\hline & 0.1 & $1.434 \pm 0.02 * *$ & $0.453 \pm 0.07$ & $0.243 \pm 0.01^{*}$ \\
\hline & 0.5 & $1.304 \pm 0.05^{*}$ & $0.491 \pm 0.18$ & $0.254 \pm 0.03^{*}$ \\
\hline & 1.0 & $1.352 \pm 0.14$ & $0.483 \pm 0.12$ & $0.255 \pm 0.04^{*}$ \\
\hline \multirow[t]{6}{*}{$\mathrm{NiO}$} & 0.0125 & $1.581 \pm 0.10$ & $0.590 \pm 0.03 *$ & $0.273 \pm 0.12$ \\
\hline & 0.025 & $1.579 \pm 0.38$ & $0.568 \pm 0.02 *$ & $0.251 \pm 0.01^{*}$ \\
\hline & 0.05 & $1.452 \pm 0.30$ & $0.646 \pm 0.15$ & $0.269 \pm 0.03 *$ \\
\hline & 0.1 & $1.374 \pm 0.16$ & $0.583 \pm 0.05^{* *}$ & $0.263 \pm 0.05^{*}$ \\
\hline & 0.5 & $1.396 \pm 0.09$ & $0.521 \pm 0.18$ & $0.274 \pm 0.16$ \\
\hline & 1.0 & $1.162 \pm 0.19$ & $0.613 \pm 0.15$ & $0.252 \pm 0.03^{*}$ \\
\hline
\end{tabular}

The $\mathrm{Ni}^{0}$ nanoparticles had an effect on the content of both forms of chlorophyll $(a+b)$ in plants of $T$. vulgare comparable to that of CuO NPs. On average, the value decreased by $18.5 \%$, and with an increase in the metal concentration in the media, the effect was enhanced. It was found that chlorophyll $b$ is more susceptible to the $\mathrm{Ni}^{0}$ NPs. In the test option, a dramatic decrease in its amount (by 16.0-68.0 \%) was observed: at a minimum concentration $(0.0125 \mathrm{M})$ of the $\mathrm{Ni}^{0} \mathrm{NPs}$, the parameters were similar to the control $(\mathrm{p}=0.01)$ followed by a dose-dependent decrease by $45.5 \%(\mathrm{p}<0.05), 54.0 \%(\mathrm{p}=0.001)$, and $68.0 \%(\mathrm{p}<0.05)$ in the presence of $0.05,0.1$ and $1.0 \mathrm{M} \mathrm{Ni}^{0} \mathrm{NPs}$. The chlorophyll $a$ content was no more than $10.0 \%$ reduced compared to control (up to $1.434-1.452 \mathrm{mg} / \mathrm{g}$ wet weight vs. $1.585 \pm 0.04 \mathrm{mg} / \mathrm{g}$ in the control) (see Table 2). Nanoparticles of $\mathrm{NiO}$ exerted an insignificant inhibitory effect, which was manifested in a decrease in the content of chlorophylls $a+b$ by $8.7 \%$ as compared to the control. The amount of chlorophyll $b$ was similar to that in the control, not only at initial concentrations of nickel oxide $(0.0125$ and $0.025 \mathrm{M}$, 
$\mathrm{p} \leq 0.05)$, but also at $0.1 \mathrm{M}(\mathrm{p}<0.01)$. At the same time, a decrease in the amount of chlorophyll $a$ lowered down to $36.0 \%$ in comparison to the control. One of the reasons for this might be the limited transport of the NiO NPs to the shoot from the roots.

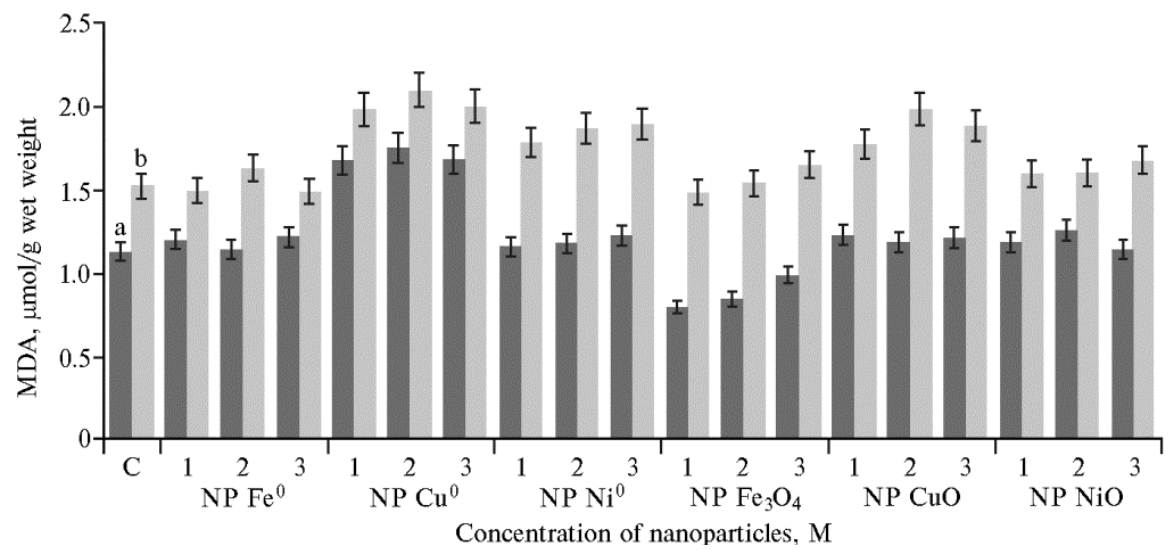

Fig. 2. The content of malonic dialdehyde (MDA) in leaves (a) and roots (b) after a 2-day incubation of wheat (Triticum vulgare L.) sprouts with nanoparticles of metals and their oxides in different concentrations: $1-0.025 \mathrm{M}, 2-0.05 \mathrm{M}, 3-0.1 \mathrm{M} ; \mathrm{C}-$ control $(\mathrm{p} \leq 0.05)$.

However, carotenoids in the leaves of the $T$. vulgare sprouts appeared to be less susceptible to the NPs of metals compared to chlorophylls (see Table 2). Therefore, the accumulation of yellow pigments within the normal range (0.1$0.5 \mathrm{mg} / \mathrm{g}$ wet weight) was observed, and only in few cases there was a slight change in this value. In the option with the $\mathrm{Cu}^{0}$ NPs, the plants differed from the control ones based on the increased content of carotenoids (by 14.5\%). In contrast, a relatively small (less than $10.0 \%$ ), but a stable decrease of this value was revealed in the sprouts at concentrations of $0.05 \mathrm{M} \mathrm{CuO} \mathrm{NPs}$ and $\mathrm{Ni}^{0} \mathrm{NPs}$, as well as at $0.5 \mathrm{M} \mathrm{Fe}^{0} \mathrm{NPs}$ (by 10.0, 3.5 and $3.0 \%$, respectively).

The obtained data indicate that a very probable cause of lesser resistance to the majority of the investigated nanoparticles $\left(\mathrm{Ni}^{0}, \mathrm{Cu}^{0}\right.$ и $\left.\mathrm{CuO}\right)$ is the increasing intensity of the oxidative stress in plants influenced by metals. The assessment results demonstrated that the MDA content in the leaves and roots of the control plants was in the range from $0.79 \pm 1.01$ to $1.75 \pm 0.14$ and from $1.48 \pm 0.22$ to $2.11 \pm 1.5 \mu \mathrm{mol} / \mathrm{g}$ wet weight. In the presence of nanoparticles, this value changed in the roots more markedly than in the leaves. The effects of the $\mathrm{Fe}^{0}, \mathrm{Fe}_{3} \mathrm{O}_{4}$ and $\mathrm{NiO}$ nanoparticles led to virtually no increase in the MDA content in wheat roots (Fig. 2). In contrast, the effects of some nanoparticles, especially $\mathrm{Ni}^{0}, \mathrm{Cu}^{0}$ and $\mathrm{CuO}$, contributed to a significant accumulation of MDA in the root part of plants with an increase in the analyzed parameter by 17.0, 25.0 and $18.7 \%(\mathrm{p}<0.05)$, respectively.

A significant increase in LPO (by $33.0 \%$ vs. control) in the leaves was observed for the effects of NPs of $\mathrm{Cu}^{0}$ (see Fig. 2), correlating to an increase in the content of carotenoids (see Table 2), which under the conditions of our experiment did not probably participate in preventing the oxidation of lipid fatty acids in cell membranes. Under the same conditions, the formation of MDA at treatment with the $\mathrm{Fe}_{3} \mathrm{O}_{4}$ NPs had only a minor tendency to decrease, i.e. by $30.0 \%$ compared to control. The absence of significant changes in $\mathrm{LPO}$ in the leaves after exposure to the $\mathrm{Ni}^{0}, \mathrm{CuO}$ and $\mathrm{NiO}$ nanoparticles can also be due to a decrease in the carotenoid pool (see Table 2).

Therefore, the obtained results allow to conclude that in wheat sprouts held for 2 days in the media containing nanoparticles, there were changes oc- 
curred in several parameters simultaneously.

The sensitivity of sprouts to nanoparticles of pure metals $\mathrm{Cu}^{0}$ and $\mathrm{Ni}^{0}$ turned out to be much higher than to their oxides $\mathrm{CuO}$ and $\mathrm{NiO}$. Of interest, none of the concentrations of the $\mathrm{CuO}$ and $\mathrm{NiO}$ NPs produced a lethal effect. All the wheat plants when exposed to the highest concentrations $(0.5$ and $1.0 \mathrm{M})$ of these nanoforms remained viable, despite a significant (more than 2-fold) decrease in most growth parameters. In addition, the analysis revealed a higher sensitivity of the root system to nanoparticles as the first target for the toxic effect of metals. The NPs of metals and oxides can be arranged by increasing their toxic effect on the growth of the main root and 1st leaf of the $T$. vulgare sprouts in the following order: $\mathrm{Fe}_{3} \mathrm{O}_{4} \rightarrow \mathrm{Fe}^{0} \rightarrow \mathrm{NiO} \rightarrow \mathrm{CuO} \rightarrow \mathrm{Ni}^{0} \rightarrow \mathrm{Cu}^{0}$.

The analysis of PPs showed that the strongest negative effect on the chlorophyll $a$ content was observed for the $\mathrm{Cu}^{0}$ NPs $(22.0-33.0 \%)$, on chlorophyll $b-$ for the $\mathrm{Ni}^{0}$ NPs $(16.0-68.0 \%)$, on carotenoids - for the CuO NPs $(10.5 \%)$. These same nanoparticles caused a decrease in the total amount of chlorophylls in the sprouts, which could have a common cause associated with the development of oxidative stress, since chloroplasts are the main source of ROS generation under stress conditions. Apparently, the copper-containing nanoparticles could directly participate in the generation of hydroxyl radicals (in the Fenton and Haber-Weiss reactions) and singlet oxygen in the cells [12], which led to the oxidative destruction of pigments, or could release copper ions and thereby induce metabolic effects, such as to disrupt the stroma and grana of chloroplast membranes [13]. The data obtained are consistent with the conclusions of the studies, in which there was a general decrease in the total amount of PPs after treatment with copper oxide nanoparticles [14-16]. The decrease in the chlorophyll $a$ content without affecting the chlorophyll $b$ level has also been previously shown [16]. The observed decrease in the chlorophyll $b$ content after exposure to the $\mathrm{Ni}^{0}$ NPs is probably caused by nickel ions involved in indirect damage to the light accumulating complex [8, 17].

It appears that the changes in the carotenoids content in our experiments was due to the lower sensitivity of the enzymes involved in their synthesis to nanoparticles, and also to the active role of these pigments in the neutralization of the ROS.

When analyzing the quantitative changes in LPO products, it can be concluded that the processes of lipid peroxidation when exposed to the ironcontaining nanoparticles are insignificant and hardly differ from those in intact plants, which indicates a non-significant development of oxidative stress [9, 18]. This can be explained by the primary non-specific response to stress as one of the components of passive adaptation of the plant. The accumulation of oxidized fatty acid products was detected in the roots, as influenced by the $\mathrm{Cu}^{0}, \mathrm{Ni}^{0}$ and $\mathrm{CuO}$ nanoparticles. Other researchers have obtained similar data for the $\mathrm{Cu}^{0}$ and $\mathrm{CuO}$ NPs and considered LPO as one of the most important toxicity mechanisms associated with exposure to nanometals $[15,16]$.

It is known that in plants the pore size of the cell wall varies from 2 to $30 \mathrm{~nm}$ [20], while the size of ions and water molecules is about $0.28 \mathrm{~nm}$. Therefore, the studied NPs of metals remain probably on the surface and act indirectly. M. Whitby et al. [21] reported that damage to cells in plants is associated with the aggregation of NPs on their surface, which creates a barrier for apoplastic transport. However, many studies reported the possibility of the penetration of even larger NPs inside the cells, as well as the appearance of new pores for the transport of metals. For example, T.D. Deryabina [22] has proved that spherical $\mathrm{Cu}^{0} \mathrm{NPs} 80 \pm 15 \mathrm{~nm}$ in size may push through the plasmalemma and accumulate in vacuoles. 
Previously it has been reported that nanoparticles can penetrate through the cell membrane and form aggregates with cellular components [3], and their oxides can block water channels through adsorption and increase the penetration of ROS [4]. A high pool of ROS and a rise in LPO in the protoplast under the effects of $\mathrm{NiO}$ were found and it was suggested that the $\mathrm{Ni}^{2+}$ ions could generate the $\mathrm{HO}^{--}$radical in plant cells through the Haber-Weiss reaction [12]. The toxicity of $\mathrm{Cu}^{\mathrm{O}}$ and $\mathrm{CuO}$ nanoforms, as well as the $\mathrm{Cu}^{2+} / \mathrm{Cu}^{+}$ions, which were released from them, has been revealed [5]. However despite all these facts, it appeared to be impossible to accurately differentiate the effects of oxidative induction by metals, their oxides and ions. The oxidative properties of the $\mathrm{CuO}$ NPs are probably due to the good solubility of this oxide down to $\mathrm{Cu}^{2+}$ and $\mathrm{Cu}^{+}$ ions $[23,24]$. The higher toxicity of the $\mathrm{Cu}^{0}$ NPs as compared to $\mathrm{CuO}$ NPs evolves probably from their lower mobility in the media [13, 24]. In addition, it is necessary to take into account the probable interaction of NPs with biomolecules, including DNA [25].

Therefore, the investigation of the growth processes, the content of pigments and products of lipid peroxidation showed that metabolic changes in the Triticum vulgare L. wheat in the presence of nanometals and their oxides depended both on the chemical nature of the metal and on the concentration of the nanopreparation used. The results provide additional evidence on selectivity during the activation of one or another metabolic reaction determined by the properties of the nanomaterial. In addition, the redox upset in the presence of $\mathrm{Ni}^{0}, \mathrm{Cu}^{0}$ and $\mathrm{CuO}$ can be attributed to a non-specific reaction of plants, since such changes are typical for a variety of stress types.

\section{REFEREN CES}

1. Karko ne A., Ku c hitsu K. Reactive oxygen species in cell wall metabolism and development in plants. Phytochemistry, 2015, 112: 22-32 (doi: 10.1016/j.phytochem.2014.09.016).

2. Li u Y., Tourbin M., Lac hai z e S., Gu i r a d P. Nanoparticles in waste waters: hazards, fate and remediation. Powder Technol., 2014, 255: 149-156 (doi: 10.1016/j.powtec.2013.08.025).

3. L e e W.M., A n Y.J., Yo o n H., K w e o n H.S. Toxicity and bioavailability of copper nanoparticles to the terrestrial plants mung bean (Phaseolus radiatus) and wheat (Triticum aestivum): plant agar test for water-insoluble nanoparticles. Environ. Toxicol. Chem., 2008, 27: 1915-1921 (doi: 10.1897/07-481.1).

4. Gere mias R., Fat torini D., Favere V.T.D., Pedros a R.C. Bioaccumulation and toxic effects of copper in common onion Allium cepa L. Chemistry and Ecology, 2010, 26(1): 1926 (doi: 10.1080/02757540903468144).

5. Chandra R., B haragava R.N., Yad av S., Mohan D. Accumulation and distribution of toxic metals in wheat (Triticum aestivum L.) and Indian mustard (Brassica campestris L.) irrigated with distillery and tannery effluents. Journal of Hazardous Materials, 2009, 162(2-3): 1514-1521 (doi: 10.1016/j.jhazmat.2008.06.040).

6. Le bedev S.V., Korotk ova A.M., O s i p ova E.A. Influence of $\mathrm{Fe}^{0}$ nanoparticles, magnetite $\mathrm{Fe}_{3} \mathrm{O}_{4}$ nanoparticles, and iron (II) sulfate $\left(\mathrm{FeSO}_{4}\right)$ solutions on the content of photosynthetic pigments in Triticum vulgare. Russ. J. Plant Physiol., 2014, 61(4): 564-569 (doi: 10.1134/S1021443714040128).

7. Zhao L., Peng B., Hernandez-Viezcas J.A., Rico C., Sun Y., PeraltaVidea J.R. Tang X., Niu G., Jin L., Varela-Ramirez A., Zhang J.Y., $\mathrm{G}$ a rde a - T o r resde y J.L. Stress response and tolerance of Zea mays to $\mathrm{CeO}_{2}$ nanoparticles: cross talk among $\mathrm{H}_{2} \mathrm{O}_{2}$, heat shock protein, and lipid peroxidation. ACS Nano, 2012, 6(11): 9615-9622 (doi: 10.1021/nn302975u).

8. Ri c o C.M., P e ra lt a-Vid e a J.R., Garde a-Torresde y J.L. Chemistry, biochemistry of nanoparticles, and their role in antioxidant defense system in plants. In: Nanotechnology and plant sciences: nanoparticles and their impact on plants. M.H. Siddiqui, M.H. Al-Whaibi, F. Mohammad (eds.). Springer, NY, 2015: 1-17 (doi: 10.1007/978-3-319-14502-0_1).

9. Fais a 1 M., S a quibb Q., Alat a ra A.A., A l-Khedhairyb A.A., Hegazya A.K., $\mathrm{Mu}$ s a r r a t d J. Phytotoxic hazards of NiO-nanoparticles in tomato: a study on mechanism of cell death. Journal of Hazardous Materials, 2013, 250-251: 318-332 (doi: 10.1016/j.jhazmat.2013.01.063).

10. S h ly k A.A. Biokhimiya, 1968, 33(2): 275-285 (in Russ.). 
11. Sibgatullina G.V., Khaertdinova L.R., Gumerova E.A., Akulov A.N., Kostyukova Yu.A., Nikonorova N.A., Rumyan ts eva N.I. Metody opredeleniya redoks-statusa kul'tiviruemykh kletok rastenii [Detection of redox potential in cultured plant cells]. Kazan, 2011. Available http://old.kpfu.ru/f1/docs/genetic1.pdf. No date (in Russ.).

12. Poless k y a O.G. Rastitel'naya kletka $i$ aktivnye formy kisloroda [Plant cell and reactive oxygen species]. Moscow, 2007 (ISBN 978-5-98227-252-2) (in Russ.).

13. Pokh rel L.R., D ube y B. Early developmental responses of plants exposed to metals and oxides nanoparticles. In: Nanotechnology and plant sciences: nanoparticles and their impact on plants. M.H. Siddiqui, M.H. Al-Whaibi, F. Mohammad (eds.). Springer, NY, 2015: 153-165 (doi: 10.1007/978-3-319-14502-0_8).

14. Shi J., Abid A.D., Ke n ne dy I.M., H ris tova K.R., S ilk W.K. To duckweeds (Landoltia punctata), nanoparticulate copper oxide is more inhibitory than the soluble copper in the bulk solution. Environ Pollut., 2011, 159: 1277-1282 (doi: 10.1016/j.envpol.2011.01.028).

15. D i mkpa C.O., M c Le a n J.E., Latt a D.E., M a nango E., B rit t D.W., Johns o n W.P., B o y a nov M.I., Ande rs o n A.J. CuO and $\mathrm{ZnO}$ nanoparticles: phytotoxicity, metal speciation, and induction of oxidative stress in sand-grown wheat. J. Nanopart. Res., 2012, 814(9): 1125-1129 (doi: 10.1007/s11051-012-1125-9).

16. N a i r P.M., Chung I.M. Impact of copper oxide nanoparticles exposure on Arabidopsis thaliana growth, root system development, root lignificaion, and molecular level changes. Environ. Sci. Pollut. Res. Int., 2014, 21: 12709-127022 (doi: 10.1007/s11356-014-3210-3).

17. Aslani F., Bagheri S., Julkapli N.M., Juraimi A.S., Hashemi F.S.G., $\mathrm{B}$ a gh dadi A. Effects of engineered nanomaterials on plants growth: an overview. Scientific World Journal, 2014, 28: 75 (doi: 10.1155/2014/641759).

18. Ouzounidou G. The use of photoacoastic spectroscopy in assessing leaf photosynthesis under copper stress: correlation of energy storage to photosystem II fluorescence parameters and redox change of $\mathrm{P}_{700}$. Plant Sci., 1996, 113: 229-237 (doi: 10.1016/0168-9452(95)04297-0).

19. Held P. An introduction to reactive oxygen species - measurement of ROS in cells. BioTek Instruments, Inc., 2015. Available http://www.biotek.com/resources/articles/reactive-oxygenspecies.html. No date.

20. Carpita N.S. Limiting diameters of pores and the surface structure of plant cell walls. Science, 1982, 218: 813-814 (doi: 10.1126/science.218.4574.813).

21. Wh it by M., Q u i rke N. Fluid flow in carbon nanotubes and nanopipes. Nature Nanotechnology, 2007, 2: 87-94 (doi: 10.1038/nnano.2006.175).

22. D e ry abi n a T.D. Adaptivnye reaktsii $i$ predely tolerantnosti Triticum aestivum L. $i$ Allium cepa L. $k$ nanochastitsam medi $i$ zheleza. Avtoreferat kandidatskoi dissertatsii [Adaptive response and tolerance to $\mathrm{Cu}$ and $\mathrm{Fe}$ nanoparticles in Triticum aestivum L. and Allium cepa L. PhD Thesis]. Orenburg, 2015 (in Russ.).

23. Kas e mets K., Ivask A., Dubourguier H., Kahru A. Toxicity of nanoparticles of $\mathrm{ZnO}, \mathrm{CuO}$ and $\mathrm{TiO}_{2}$ to yeast Saccharomyces cerevisiae. Toxicology in Vitro, 2009, 23: 1116-1122 (doi: 10.1016/j.tiv.2009.05.015).

24. Wang Z., Xi e X., Zha o J., Liu X., Feng W., White J.C., Xing B. Xylem- and phloem-based transport of $\mathrm{CuO}$ nanoparticles in maize (Zea mays L.). Environ. Sci. Technol., 2012, 46(8): 4434-4441 (doi: 10.1021/es204212z).

25. K o r o t k ov a A., S i z o v a E., L e b e d e v S. Influence of iron nanoparticles on induction of oxidative damage in Triticum vulgare. Ecology, Environment and Conservation Paper, 2015, 21: 101-111. 